\title{
Recessive myotonia congenita caused by a homozygous splice site variant in CLCN1 gene: a case report
}

Peter Sparber * (D), Margarita Sharova, Alexandra Filatova, Olga Shchagina, Evgeniya Ivanova, Elena Dadali and Mikhail Skoblov

From 11th International Young Scientists School "Systems Biology and Bioinformatics" - SBB-2019

Novosibirsk, Russia. 24-28 June 2019

\begin{abstract}
Background: Myotonia congenita is a rare neuromuscular disease, which is characterized by a delay in muscle relaxation after evoked or voluntary contraction. Myotonia congenita can be inherited in a dominant (Thomsen disease) and recessive form (Becker disease) and both are caused by pathogenic variants in the CLCN1 gene. Noncanonical splice site variants are often classified as variants of uncertain significance, due to insufficient accuracy of splice-predicting tools. Functional analysis using minigene plasmids is widely used in such cases. Moreover, functional analysis is very useful in investigation of the disease pathogenesis, which is necessary for development of future therapeutic approaches. To our knowledge only one noncanonical splice site variant in the CLCN1 gene was functionally characterized to date. We further contribute to this field by evaluation the molecular mechanism of splicing alteration caused by the c.1582 + 5G > A in a homozygous state.

Case presentation: We report a clinical case of an affected 6-y.o boy with athletic appearance due to muscle hypertrophy, calf muscle stiffness, cramping and various myotonic signs in a consanguineous family with no history of neuromuscular disorders. The neurological examination showed percussion-activated myotonia in the hands and legs. Plasma creatine kinase enzyme and transaminases levels were normal. Electromyography at the time of examination shows myotonic runs in the upper and lower extremities.
\end{abstract}

Conclusions: Functional analysis of the variant in a minigene system showed alteration of splicing leading to loss of function, thereby confirming that the variant is pathogenic.

Keywords: Myotonia congenita, Becker disease, Functional analysis, Splicing, Case report

* Correspondence: psparber93@gmail.com

Research Centre for Medical Genetics Moskvorechie 1, Moscow 115522,

Russia

(c) The Author(s). 2020 Open Access This article is licensed under a Creative Commons Attribution 4.0 International License, which permits use, sharing, adaptation, distribution and reproduction in any medium or format, as long as you give appropriate credit to the original author(s) and the source, provide a link to the Creative Commons licence, and indicate if changes were made. The images or other third party material in this article are included in the article's Creative Commons licence, unless indicated otherwise in a credit line to the material. If material is not included in the article's Creative Commons licence and your intended use is not permitted by statutory regulation or exceeds the permitted use, you will need to obtain permission directly from the copyright holder. To view a copy of this licence, visit http://creativecommons.org/licenses/by/4.0/. The Creative Commons Public Domain Dedication waiver (http://creativecommons.org/publicdomain/zero/1.0/) applies to the data made available in this article, unless otherwise stated in a credit line to the data. 


\section{Background}

Myotonia congenita (MC) belongs to the group of nondystrophic myotonias along with paramyotonia and sodium channel myotonia. Clinically myotonia defined by muscle stiffness in various muscle groups, percussion myotonia, and the "warm-up" phenomenon (relieve in myotonia after repetitive contractions) with myotonic discharges seen on electromyography (EMG) [1]. MC is associated with pathogenic variants in the CLCN1 gene, which encode for the skeletal muscle chloride channel CLC-1 and can be inherited in a dominant or recessive trait. The recessive form of MC (Becker disease OMIM \#255700) typically has a more severe phenotype and is considered to be more widespread than the dominant one (Thomsen disease - OMIM \#160800) [2].

The overall prevalence of MC is 1:100'000 according to the Orphanet database [3]. However the prevalence of MC can be as high as 1:10'000 in Northern Finland [4]. The disease onset of recessive $\mathrm{MC}$ is usually in the first or the second decade of life starting with painless myotonia in the lower limbs and progresses to the arms, facial muscles and neck. Patients can have an athletic appearance due to muscle hypertrophy. Transient muscular weakness is also a common feature.

We are reporting a clinical case of a Turkmen consanguineous family where a 6-y.o boy at the time of examination had calf muscle stiffness with periodic muscle spasms and various myotonic phenomena's without signs of muscle dystrophy. Sanger sequencing of the CLCN1 gene identified a homozygous variant at the intron 14 - c. $1582+5 \mathrm{G}>$ A. Functional analysis in a minigene system was performed in order to evaluate the impact of the variant on splicing.

\section{Case presentation}

A family of Turkmen origin was referred to genetic consultation for progeny prediction. One of their three children - a 6-year old boy was examined due to calf muscle stiffness and cramping in various muscle groups. The proband was born in consanguineous marriage - his parents were third cousins. Gestation and delivery were uneventful. He developed normally for the first year of life when painless muscle stiffness of the calf muscle was first noticed. The parents had two healthy daughters without any neurological signs. No history of neuromuscular disorders was present in the family.

Upon examination at the age of six, the proband had an athletic appearance due to muscle hypertrophy. The neurological examination showed percussion-activated myotonia in the hands and legs. After a maximum voluntary contraction of the hand, the proband could not fully open his fist, but repeated attempts improve myotonia due to the warm-up phenomenon. Plasma creatine kinase enzyme and transaminases levels were normal.
Electromyography shows myotonic runs in biceps brachii, vastus lateralis and tibialis anterior muscles.

Based on the clinical findings a recessive form of $\mathrm{MC}$ was suspected. Sanger sequencing of all CLCN1 exons and the nearest intron regions was performed. It revealed a homozygous variant in the intron 14 of the CLCN1 gene - c.1582 + 5G > A. Following segregation analysis in the family showed that both parents are heterozygous for this variant (Fig.1).

Homozygous or compound heterozygous pathogenic variants in the $C L C N 1$ gene lead to recessive $\mathrm{MC}$ also known as Becker disease. c. $1582+5 \mathrm{G}>\mathrm{A}$ variant was described as pathogenic in a previous work [5]. However, no functional studies were made to confirm the functional consequences of the discovered variant and according to ACMG guidelines this variant should be classified as a "variant of uncertain significances" (VUS) [6]. This means that we cannot be sure about the pathogenic role of the described variant and his causality. In silico analysis using Human Splicing finder 3.1 [7] predicted a broken wild-type donor site.

In order to determine the impact of the described variant on splicing, we performed a minigene-splicing assay. We cloned the entire 14 exon with the flanking intronic sequences containing the variant of interest into pSpl3Flu plasmid [8] and transfected HEK293T cells. Subsequent RT-PCR analysis with plasmid-specific primers showed that the presence of c. $1582+5 \mathrm{G}>\mathrm{A}$ variant lead to two independent pathogenic splicing alterations (Fig. 2). Sanger sequencing of RT-PCR products revealed that c. $1582+5 \mathrm{G}>\mathrm{A}$ variant disrupt the donor splice site (SS) of intron 14, which leads to activation of two upstream exonic cryptic SS. The activation of the first cryptic SS causes a 57-nucleotide truncation of exon 14 $(\Delta 57)$ resulted in an in-frame deletion of 19 amino acids (p.(Gly509_ Ile527del)). These 19 amino acids encode for part of the fifteenth transmembrane $\alpha$-helices of CLC1 channel (helix O) and other pathogenic missense variants were described in this exon leading to $\mathrm{MC}[9,10]$. The second pathogenic splicing event is a 91-nucleotide truncation of exon $14(\Delta 91)$ that leads to a frame-shift (p.(Val498GlufsTer5)) and a formation of a premature stop codon (PTC). Such mRNA isoform should be degraded by nonsense-mediated decay (NMD) [11]. According to functional investigation missense variants in exon 14 of the CLCN1 gene are considered to be similar to loss of function (LoF) variants based on their effect on channel conductance [12]. This means that in our case both splicing alterations are predicted to cause LoF of CLC-1 protein. Thereby after performing functional study according to the ACMG guidelines we reclassify c.1582+5G > A variant as a class $4-$ likely pathogenic (criteria PM2, PP3 and PS3). 

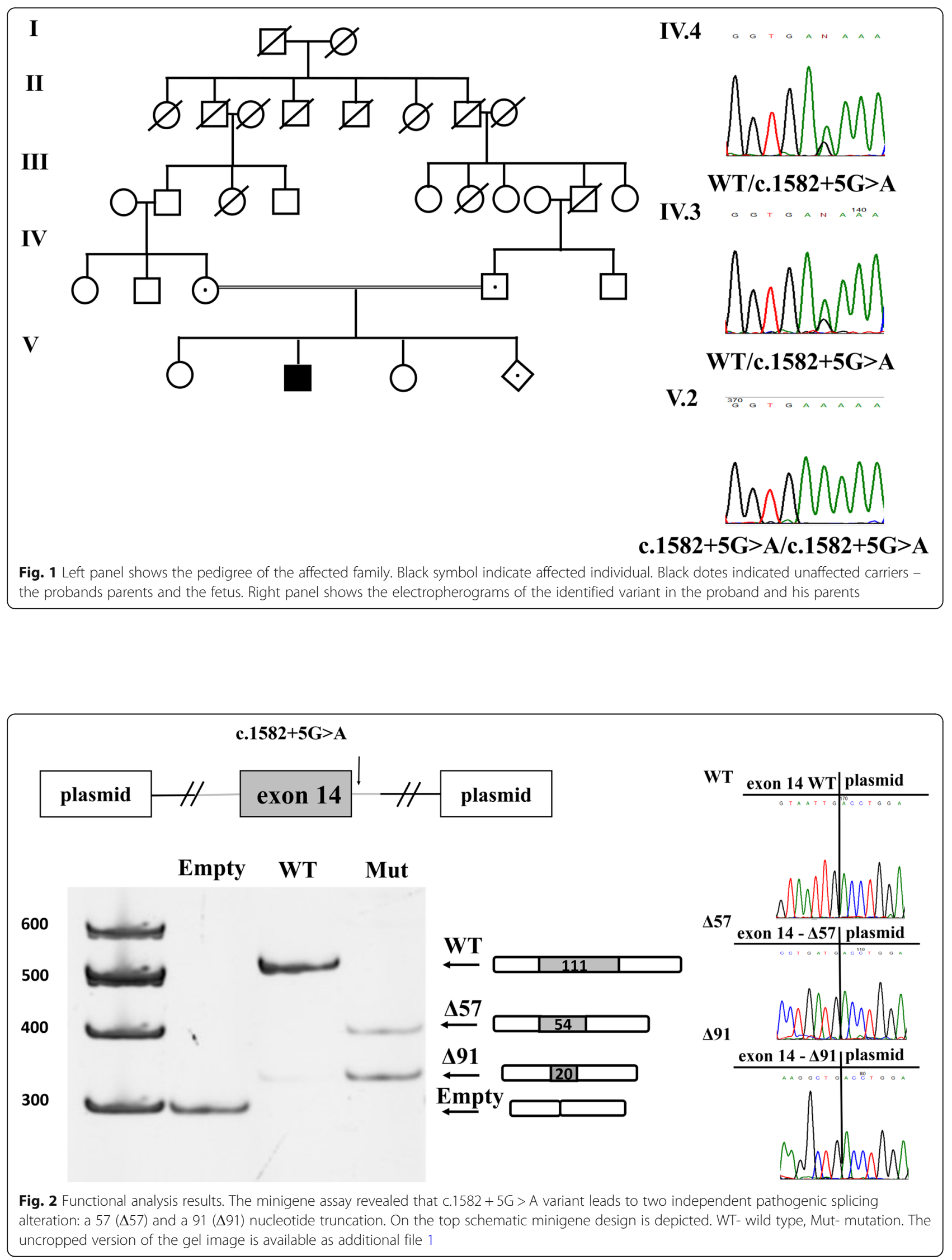


\section{Discussion and conclusions}

CLC-1 is the most abundant chloride channel expressed predominantly on the sarcolemma of skeletal muscles and plays a key role in excitability regulation. In human muscles, up to $80 \%$ of the resting membrane conductance is contributed by chloride conductance [13]. The chloride channels in muscle cells are activated after an action potential and are necessary for restoring the resting membrane potential. If the chloride channels fail to activate, $\mathrm{K}^{+}$starts to accumulate in the extracellular space, which leads to membrane depolarization that at a certain level can initiate self-activation resulting in a prolonged muscle constriction that is observed in myotonia patients [14].

To date 280 pathogenic variants in CLCN1 are described according to HGMD professional database and include missense, nonsense, splicing substitutions, and frameshift variants. Different pathogenic variants can lead to different forms of $\mathrm{MC}$. The recessive form of $\mathrm{MC}$ is associated with biallelic LoF variants that can be found across all gene body, except for truncation variants located close to the $\mathrm{C}$-terminus. Missense pathogenic variants can lead to both recessive and dominant MC. Dominant MC is associated with missense variants, and truncating variants, escaping NMD leading to a dominant-negative effect on CLC-1 homodimer channel [2].

Because of the diversity in the molecular bases of $\mathrm{MC}$, it is rather difficult to establish the mode of inheritance based on the patient's genotype and only functional investigations can resolve this issue. Moreover, functional studies increase our knowledge in understanding the pathogenesis of $\mathrm{MC}$, which is crucial for more precise genetic counseling and developing future therapeutic approaches. Aberrant splicing is known to cause $\mathrm{MC}$, however, it is very difficult to interpret variants that lay outside of the canonical SS dinucleotide. These intronic variants are often classified as VUS and evaluating their functional consequences is very important especially for families that consider procreation.

The most informative results for splicing analysis are obtained by using RT-PCR analysis from a diseaserelevant tissue. Unfortunately, in many cases, it is not possible to perform such analysis for many reasons including medical and ethical issues. Nevertheless, several publications including the work of van der Klift et al. [15] showed that minigenes assays are highly concordant with patient RNA analysis in terms of rather or not the variant is pathogenic. In our case, the minigene assay revealed complete absence of the WT transcript and the presence of two aberrant isoforms. Further analysis of the mutated isoforms and their effect on the protein level led us to the conclusion that both transcripts should lead to a LoF which is the main pathogenic mechanism in recessive MC.
Here we present a clinical report of a proband with recessive form of $\mathrm{MC}$ in a consanguineous family with a variant affecting splicing in a homozygous state. This variant was reported as pathogenic before, however, no functional conformation was performed. Due to the fact that the proband mother was pregnant, we decided to functionally investigate this variant for performing proper prenatal diagnosis. By splicing minigene assay, we confirmed the pathogenic role of the splicing variant on the molecular level. At 10-11 weeks of gestation, a prenatal diagnosis was performed from chorion villi samples showing that the fetus is a heterozygous carrier of c. $1582+5 \mathrm{G}>\mathrm{A}$ variant.

\section{Supplementary information}

Supplementary information accompanies this paper at https://doi.org/10. 1186/s12881-020-01128-5.

Additional file 1. Uncropped version of the gel image in Fig. 2

\begin{abstract}
Abbreviations
MC: Myotonia congenital; CLCN1: Chloride voltage-gated channel 1; LoF: Loss of function; VUS: Variant of uncertain significances;

EMG: Electromyography; ACMG: American college of medical genetics; NMD: Nonsense-mediated decay; HGMD: Human gene mutation database; HGVS: Human genome variation society; OMIM: Online mendelian inheritance in man
\end{abstract}

\section{Acknowledgements}

Not applicable.

\begin{abstract}
About this supplement
This article has been published as part of BMC Medical Genetics Volume 21 Supplement 1, 2020: Selected Topics in "Systems Biology and Bioinformatics" - 2019: medical genetics. The full contents of the supplement are available online at https://bmcmedgenet.biomedcentral.com/articles/supplements/ volume-21-supplement-1
\end{abstract}

\section{Authors' contributions}

PS performed the functional analysis and wrote the manuscript. MS performed the functional analysis. AF-wrote and revised the manuscript. OS - analysed the Sanger sequencing data. El- performed the PCR and Sanger sequinning of the CLCN1 gene. ED - performed the clinical examination of the patient. MS - wrote and revised the manuscript. All authors read and approved the final manuscript.

\section{Funding}

Publication costs have been funded by Ministry of Science and Higher Education of the Russian Federation. The funders had no role in study design, data collection and analysis, decision to publish, or preparation of the manuscript.

\section{Availability of data and materials}

The datasets used and analysed during the current study are available from the corresponding author upon reasonable request. c.1582 + 5G > A variant was submitted to LOVD database. Variant ID \#0000598290.

\section{Ethics approval and consent to participate}

This study was approved by the Institutional Review Board of the Research Centre for Medical Genetics, Russia and was performed in accordance with the Declaration of Helsinki. For this work written informed consent was obtained from all participants. For participants under 16 years old written informed consent was obtained from the participant's parent. 


\section{Consent for publication}

For this work written informed consent was obtained from all participants for the clinical examination and the publication of their anonymized data and publication of identifying images. For participants under 16 years old written informed consent was obtained from the participant's parent. No identifying images were used in this work.

\section{Competing interests}

The authors declare that they have no competing interests.

Published: 22 October 2020

\section{References}

1. Sansone, V.A., The Dystrophic and Nondystrophic Myotonias. Continuum (Minneap Minn), 2016. 22(6, Muscle and Neuromuscular Junction Disorders): p. $1889-1915$.

2. Fialho D, et al. Chloride channel myotonia: exon 8 hot-spot for dominantnegative interactions. Brain. 2007;130(Pt 12):3265-74.

3. Orphanet Report Series - Prevalence of rare diseases: Bibliographic data - June 2018 - Number 1.

4. Papponen $\mathrm{H}$, et al. Founder mutations and the high prevalence of myotonia congenita in northern Finland. Neurology. 1999;53(2):297-302.

5. Ivanova $\mathrm{EA}$, et al. The spectrum of CLCN1 gene mutations in patients with nondystrophic Thomsen's and Becker's myotonias. Genetika. 2012;48(9): 1113-23.

6. Richards S, et al. Standards and guidelines for the interpretation of sequence variants: a joint consensus recommendation of the American College of Medical Genetics and Genomics and the Association for Molecular Pathology. Genet Med. 2015;17(5):405-24.

7. Desmet FO, et al. Human splicing finder: an online bioinformatics tool to predict splicing signals. Nucleic Acids Res. 2009;37(9):e67.

8. Filatova AY, et al. Functional reassessment of PAX6 single nucleotide variants by in vitro splicing assay. Eur J Hum Genet. 2019;27(3):488-93.

9. Moon IS, et al. Novel CLCN1 mutations and clinical features of Korean patients with myotonia congenita. J Korean Med Sci. 2009;24(6):1038-44.

10. Tincheva S, et al. Myotonia congenita type Becker in Bulgaria: first genetically proven cases and mutation screening of two presumable endemic regions. Neuromuscul Disord. 2016;26(10):675-80.

11. Pereverzev AP, et al. Method for quantitative analysis of nonsense-mediated mRNA decay at the single cell level. Sci Rep. 2015;5:7729.

12. Ha K, et al. Electrophysiological characteristics of six mutations in hClC-1 of Korean patients with myotonia congenita. Mol Cells. 2014;37(3):202-12.

13. Bryant SH, Morales-Aguilera A. Chloride conductance in normal and myotonic muscle fibres and the action of monocarboxylic aromatic acids. J Physiol. 1971;219(2):367-83.

14. Tang CY, Chen TY. Physiology and pathophysiology of CLC-1: mechanisms of a chloride channel disease, myotonia. J Biomed Biotechnol. 2011;2011: 685328.

15. van der Klift HM, et al. Splicing analysis for exonic and intronic mismatch repair gene variants associated with lynch syndrome confirms high concordance between minigene assays and patient RNA analyses. Mol Genet Genomic Med. 2015;3(4):327-45.

\section{Publisher's Note}

Springer Nature remains neutral with regard to jurisdictional claims in published maps and institutional affiliations.

\section{Ready to submit your research? Choose BMC and benefit from:}

- fast, convenient online submission

- thorough peer review by experienced researchers in your field

- rapid publication on acceptance

- support for research data, including large and complex data types

- gold Open Access which fosters wider collaboration and increased citations

- maximum visibility for your research: over $100 \mathrm{M}$ website views per year

At BMC, research is always in progress.

Learn more biomedcentral.com/submissions 